\title{
Burden, risk assessment, surveillance and management of SARS-CoV-2 infection in health workers: a scoping review
}

\author{
Federica Calò, Antonio Russo, Clarissa Camaioni, Stefania De Pascalis and Nicola Coppola* (1)
}

\begin{abstract}
Background: Health workers (HWs) are at increased risk for severe acute respiratory syndrome-coronavirus-2 (SARSCoV-2) infection and a possible source of nosocomial transmission clusters. Despite the increased risk, the best surveillance strategy and management of exposed HWs are not yet well known. The aim of this review was to summarize and critically analyze the existing evidence related to this topic in order to support public health strategies aimed at protecting HWs in the hospital setting.

Main text: A comprehensive computerized literature research from 1 January 2020 up to 22 May 2020 was made to identify studies analyzing the burden of infection, risk assessment, surveillance and management of HWs exposed to SARS-CoV-2. Among 1623 citation identified using MEDLINE, Embase, Google Scholar and manual search, we included 43 studies, 14 webpages and 5 ongoing trials.

Health workers have a high risk of acquiring infection while caring for coronavirus disease 2019 (COVID-19) patients. In particular, some types exposures and their duration, as well as the inadequate or non-use of personal protective equipment (PPE) are associated with increased infection risk. Strict infection prevention and control procedures $(I P C)$, adequate training programs on the appropriate use of PPE and close monitoring of HWs with symptom surveillance and testing are essential to significantly reduce the risk. At the moment there is not enough evidence to provide precise indications regarding pre-exposure prophylaxis (PrEP) and post-exposure prophylaxis (PEP).

Conclusions: During the spread of COVID-19 outbreak, numerous published papers investigated the epidemiology, risk assessment and prevention and control of SARS-CoV-2. However, more high-quality studies are needed to provide valid recommendations for better management and for the clinical and microbiological surveillance of healthcare personnel.
\end{abstract}

Keywords: Healthcare worker, Health worker, Risk assessment, Surveillance, Management, COVID-19

\section{Background}

The severe acute respiratory syndrome-coronavirus-2 (SARS-CoV-2), the virus that causes the coronavirus disease (COVID-19), has rapidly worldwide, so on 3 June 2020 approximately 6348900 cases of COVID-19 were reported worldwide, with about 380810 deaths [1].

\footnotetext{
*Correspondence: nicola.coppola@unicampania.it

Department of Mental Health and Public Medicine - Infectious Diseases Unit, University of Campania Luigi Vanvitelli, L. Armanni 5, 80131 Naples, Italy
}

Current evidence suggests that SARS-CoV-2 is transmitted from person to person through close contact and droplets. People most at risk of acquiring the disease are those who are in contact with or care for patients with COVID-19. This inevitably places health workers (HWs) at a high risk of infection [2-4], citing them as a possible source of nosocomial transmission clusters. In fact, since the pandemic started, healthcare facilities are high-risk places of infection, and some studies report outbreaks in some of these [5-7]. Therefore, knowing the main

\section{$\triangle B M C$}

(C) The Author(s). 2020 Open Access This article is licensed under a Creative Commons Attribution 4.0 International License, which permits use, sharing, adaptation, distribution and reproduction in any medium or format, as long as you give appropriate credit to the original author(s) and the source, provide a link to the Creative Commons licence, and indicate if changes were made. The images or other third party material in this article are included in the article's Creative Commons licence, unless indicated otherwise in a credit line to the material. If material is not included in the article's Creative Commons licence and your intended use is not permitted by statutory regulation or exceeds the permitted use, you will need to obtain permission directly from the copyright holder. To view a copy of this licence, visit http://creativecommons.org/licenses/by/4.0/ The Creative Commons Public Domain Dedication waiver (http://creativecommons.org/publicdomain/zero/1.0/) applies to the data made available in this article, unless otherwise stated in a credit line to the data. 
transmission modes and assessing the risk of HWs are of utmost importance to prevent nosocomial transmission.

As regards the transmission modes of SARS-CoV-2, apart from the known routes such as contact and droplets [8], little evidence is at present reported on aerosol transmission, contaminated environments, the ocular surface and fecal-oral routes as a means of occupational exposure. Considering aerosol transmission, although some studies show the presence of SARS-CoV-2 RNA in aerosols, with lower values in isolated negatively pressurized rooms with high air exchange rate, and higher values in small rooms without ventilation (e.g. patient's toilet) [9], there is no evidence that SARS-CoV-2 is spread by airborne route [10]. However, it is reported how some procedures produce aerosol with different risks of aerosolization [10]: bronchoscopy, percutaneous tracheostomy and cardiopulmonary resuscitation have an estimated extreme risk of aerosol generation; suctioning, and extubation have a high estimated risk of aerosol generation, while oxygen facemasks, high-flow cannula, non-invasive ventilation and nebulizers have a high to moderate risk [10].

Based on the routes of transmission, current personal protective equipment (PPE) and infection control guidelines $[8,11,12]$ have been published and updated giving directives on how to protect the healthcare personnel from infection. In general, isolation gown and gloves are recommended as a contact precaution, and eye protection and surgical masks or filtering face piece-FFP2- (or equivalent) are recommended as a droplet precaution $[8,11,12]$. Airborne precautions, which include the use of FFP3 (or equivalent), are limited for aerosol generating procedures. Furthermore, the guidelines suggest strict procedures for putting on and safely removing PPE $[8,11,12]$.

United States Centre for Disease Control (CDC) and European Centre for Disease Prevention and Control (ECDC) guidelines $[11,12]$ indicates in sequence to putting on, after carefully choose the right PPE, as first the gown, followed by the filtering face piece respirator or facemask, face shield or googles, the gloves. For safely remove the PPE the sequence advised include to put off as first the gloves and the gown, followed by the face shield, the filtering face piece respirator or facemask. Moreover, ECDC define a contact of a COVID-19 case any person, including a HW, who has had contact with a COVID-19 case within a time frame ranging from $48 \mathrm{~h}$ before the onset of symptoms of the case to 14 days after the onset of symptoms [13].

As for other HWs, forensics workers are considered at risk of infection, especially during autopsies or managing specimens of COVID-19 patients [14-18]. Generally, PPE used in this setting are similar with some difference. Double surgical gloves interposed with a lyer of cut- proof synthetic mesh gloves, gown fluid resistant or impermeable, waterproof apron, googles or face shield, and filtering face piece respirator or facemask [14]. The guidelines also indicate the correct procedures for sample collection and material disposal [14].

As regards the assessment of risks to HWs, there is a lack of infection surveillance data and unknown or scanty data on the most appropriate way of preventing nosocomial transmission. Therefore, due to the importance of healthcare facilities in the transmission of SARS$\mathrm{CoV}-2$ worldwide, it is clear that strict infection prevention and control (IPC) procedures, adequate training programs on the appropriate use of PPE and close monitoring of HWs are critical for occupational safety. In addition to being potentially at increased risk of infection with COVID-19, HWs may be responsible for nosocomial outbreaks and may transmit SARS-CoV-2 to vulnerable patients $[19,20]$.

This scoping review article will focus on the risks of HWs acquiring SARS-CoV-2 infection while carrying out their occupational duties and on the surveillance and management of exposed HWs. The aim was to summarize and critically analyze the existing evidence related to this topic in order to support public health strategies aimed at protecting HWs in the hospital setting.

\section{Methods}

\section{Search strategy}

A comprehensive computerized literature research was made to identify studies analyzing risk assessment, surveillance and management of HWs exposed to SARSCoV-2 using MEDLINE, Embase, Google Scholar, involving both medical subject heading $(\mathrm{MeSH})$ terminology and relevant keywords for search strings to locate articles that analyzed the infection-control procedures for COVID-19 in healthcare facilities.

The following items were used to search for the studies: "health workers", "healthcare personnel", "infectioncontrol", "pre-exposure prophylaxis", "post-exposure prophylaxis" "HCW", "HCP" and "COVID-19", "SARSCoV-2". In addition, the reference lists of all studies meeting the inclusion criteria, of the studies excluded and of the published review articles were manually searched to identify any other study that might merit inclusion. We performed a manually search in CDC, ECDC, World Health Organization (WHO), Clinicaltrials.gov, and European Ministry of Health website in order to include relevant citations.

\section{Inclusion and exclusion criteria}

Due to the rapid spread of the COVID-19 pandemic, the review included studies related to health workers published between 1 January up to 22 May 2020. We included without restrictions guidelines, original article, 
meta-analysis, letters to editor, editorials, reviews, clinical studies and epidemiological studies, in addition to peer-reviewed publications. Data provided by international organisations and government institutions were also included. All the studies discussing the risk assessment, surveillance and management of HWs exposed to SARS-CoV-2, were included.

Exclusion criteria were a) studies published before 1 January 2020; b) meeting abstract, meeting papers.

\section{Selection of studies and data extraction}

Three researchers (FC, AR and CC) working independently extracted the data according to the inclusion criteria. Disagreements on the inclusion or exclusion of literature were resolved through discussion. The following relevant information was collected from every article selected according to the inclusion criteria: last name of the first author, year and name of journal of publication, country where the population was investigated, study design and topic. Duplicate articles were eliminated.

\section{Synthesis of results}

Based on the main research objectives, articles were classified into one of the following research topics: epidemiology, risk factors and prevention and control, diagnosis and surveillance, management. "Epidemiology" included studies on the epidemic distribution of SARS-CoV-2 in HWs; "risk factors and prevention and control" included studies on risk assessment, transmission patterns and IPC procedures; "diagnosis and surveillance" included studies on microbiological diagnosis and surveillance of
HWs exposed to COVID-19; and "management" included studies on pre and post-exposure prophylaxis measures.

\section{Results and discussion}

The flow diagram (Fig. 1) shows the process of identification and selection of the articles included in the metaanalysis. Using MEDLINE, Embase and Google scholar we identified 1624 citations; of these 43 (8 from manual search) were the most comprehensive for our outcome. From WHO, CDC, ECDC, European ministry of health we selected 14 webpages or reports. We manually searched on Clinicaltrial.gov and included 5 ongoing studies following our outcome.

\section{Burden of SARS-CoV-2-infection in HWs}

In several countries worldwide, the proportion of COVID-19 cases among healthcare professionals was reported as highly variable (Table 1 ).

Of the all confirmed cases in China, about $3.8 \%$ were HWs with the majority of cases (88\%) reported from Hubei [26, 27]. Indeed, through 25 February 2020, 3387 SARS-CoV-2 positive HWs were reported in Hubei, at least 18 of whom died [28]. Another report from a single-center case series of 138 hospitalized COVID-19 patients in Wuhan, China, in January 2020 found that $29 \%(40 / 138)$ were HWs infected in hospital [29].

In Italy of the 228418 confirmed COVID-19 cases, from $11.9 \%$ up to $20 \%$ were reported in healthcare personnel [22, 25, 27]. In Spain, the latest COVID-19 situation overview from the Ministry of Health showed

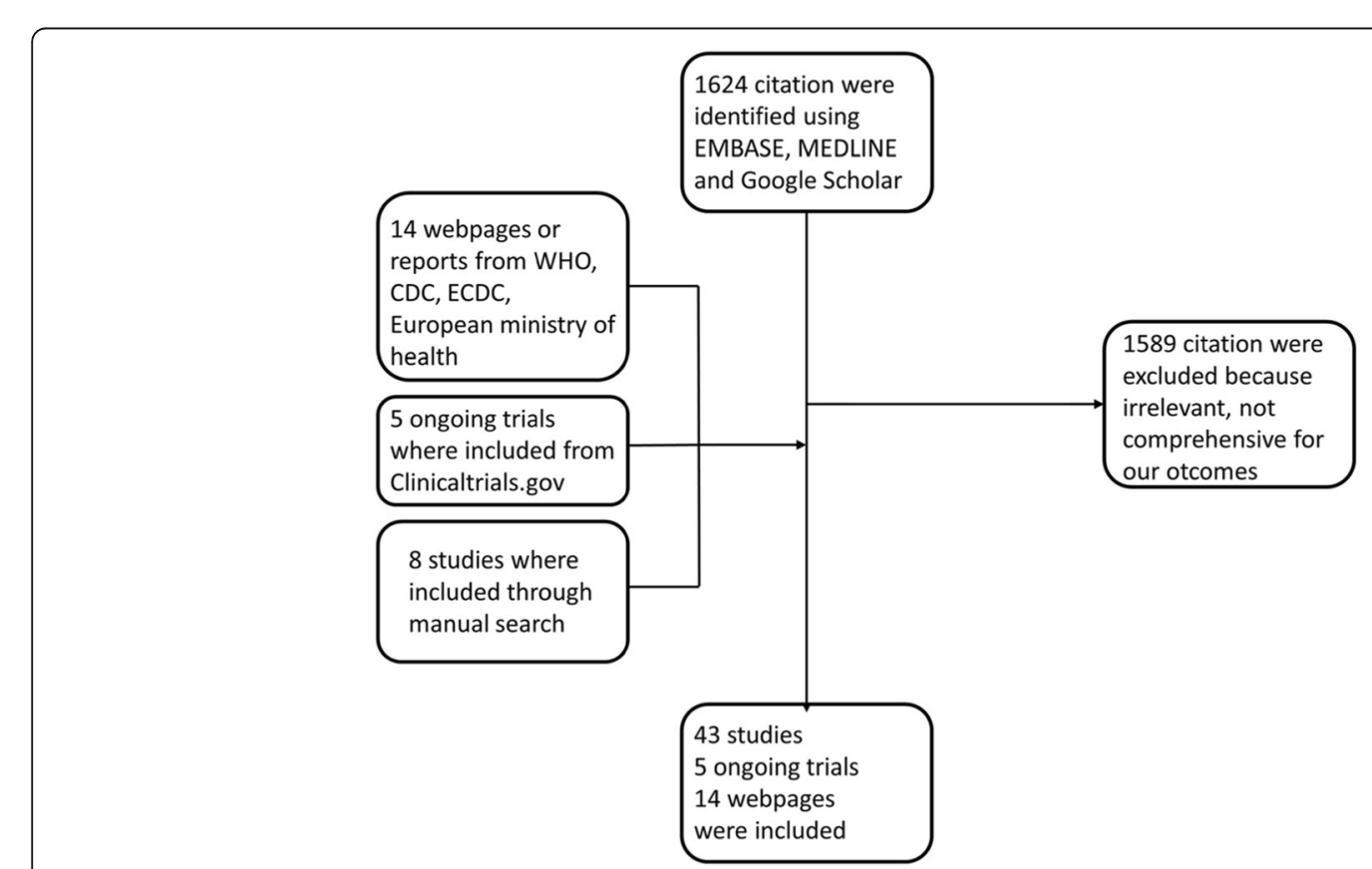

Fig. 1 Flow chart of studies selection 
Table 1 Burden of SARS-COV-2 infection in health workers (HWs) in different studies

\begin{tabular}{|c|c|c|c|c|c|c|c|}
\hline \multirow{2}{*}{$\begin{array}{l}\text { Author, reference } \\
\text { number }\end{array}$} & \multirow[t]{2}{*}{ Country } & \multirow[t]{2}{*}{ Type of study } & \multicolumn{2}{|c|}{ Studies in general population } & \multicolumn{2}{|c|}{ Studies in HWs } & \multirow[t]{2}{*}{ Notes } \\
\hline & & & $\begin{array}{l}\text { Number of } \\
\text { COVID-19 } \\
\text { patients }\end{array}$ & $\begin{array}{l}\text { Number (\%) of } \\
\text { HWs COVID-19 }\end{array}$ & $\begin{array}{l}\text { Number of } \\
\text { HWs tested }\end{array}$ & $\begin{array}{l}\text { Number (\%) of } \\
\text { HWs COVID-19 }\end{array}$ & \\
\hline Kang et al., [16] & Korea & National Registry & 10062 & $241(2.4)$ & - & - & $\begin{array}{l}\text { Data updated } \\
\text { to } 5 \text { April } 2020\end{array}$ \\
\hline Rivett et al., [21] & United Kingdom & Cohort study & - & - & 1032 & $30(3)$ & - \\
\hline Reusken et al., [22] & Netherlands & Cohort study & - & - & 1097 & $45(4.1)$ & - \\
\hline Kluytmans et al., [23] & Netherlands & Cohort study & - & - & 1353 & $86(6)$ & - \\
\hline Ministry of Health, [17] & Italy & National Registry & 228418 & $27101(11.9)$ & - & - & $\begin{array}{l}\text { Data updated } \\
\text { to } 22 \text { May } 2020\end{array}$ \\
\hline Hunter et al., [24] & United Kingdom & Cohort study & - & - & 1654 & $240(14)$ & - \\
\hline Ministry of Health, [19] & Spain & National Registry & 250287 & 40921 (16.3\%) & - & - & $\begin{array}{l}\text { Data updated } \\
\text { to } 21 \text { May } 2020\end{array}$ \\
\hline Keeley et al., [11] & United Kingdom & Cohort study & - & - & 1533 & $282(18)$ & - \\
\hline Wang et al., [15] & China & $\begin{array}{l}\text { Retrospective, } \\
\text { single- center } \\
\text { case series }\end{array}$ & 138 & $40(29)$ & - & - & - \\
\hline Folgueira et al., [25] & Spain & Cohort study & - & - & 2085 & 791 (38) & - \\
\hline
\end{tabular}

- data not reported

that among the 250287 COVID-19 cases, 40921 (16.3\%) were HWs [24]. In the US, the reported cases of COVID-19 among HWs ranged from 3 to $11 \%$, depending on the states with more complete reporting [30]. From an overall 1423 SARS-CoV-2-positive HWs, 55\% reported a known contact with a confirmed COVID-19 patient in the 14 days before the illness onset [30].

The different prevalence of SARS-CoV-2 infection in HW in the different countries may be explained by several factors. For example, by the different prevalence of SARS-CoV-2 infection in the general population, the different IPC procedures and positive tracking protocol used. Moreover, different seems to be the prevalence of SARS-CoV-2 infection in HW compared to that observe during severe acute respiratory syndrome (SARS) and Middle East respiratory syndrome coronavirus (MERS) epidemics. In fact, HWs accounted for a large proportion of persons with SARS during the worldwide epidemic of early 2003, accounting for $21 \%$ of over 8000 known cases reported from 33 countries in 5 continents [31]. As regards MERS, the majority of cases were registered in Saudi Arabia, the United Arab Emirates and Republic of Korea [32-34]. In Saudi Arabia, 19.1\% of all cases of MERS reported from January 2013 to November 2019 were HWs [35]. As of 5 April 2020, the Korea Centers for Disease Control and Prevention (KCDC) reported 241 COVID-19 cases in HWs, 101 infected at work, among a total of 10062 COVID-19 cases, suggesting a less rate of COVID-19 infection in HWs comparing to that observed for MERS (2.4\% vs $21 \%$ ) [36]. They attribute this lower rate of infection despite an higher reproductive number $\left(R_{0}\right)$ ranging from 2 to 5.7 for SARS-
CoV-2 to $<1$ for MERS, to a better management of suspected patients and the management of COVID-19, the widely use of PCR test, implementation of contact tracking, the implementation of epidemiological team, the training in good practices and the proper use of PPE including, the practice of wearing mask both in hospital staff and visitors [36]. However, the cases reported among healthcare professionals are not always the expression of occupational exposure. For example, in a study [37] carried out in the Netherlands in nine hospitals from 6 to 8 March 2020, a total of 1097 HWs without a known epidemiological link for professional COVID-19 exposure (close contact with confirmed case) were tested for SARS-CoV-2, of whom 45 (4.1\%) were found positive. A Spanish study [38] conducted in a large public hospital in March 2020 found a rate of SARS-CoV-2 infection in 38\% of HWs tested and $11.6 \%$ in all hospital workers; interestingly, no significant difference in the SARS-CoV-2 infection was observed between HWs from high-risk areas involved in close contact with COVID-19 patients and clerical, administrative or laboratory personnel without direct contact with patients. Similarly, the Newcastle upon Tyne Hospitals NHS Foundation Trust screened staff with compatible symptoms (i.e., new continuous cough or fever) and found no difference in SARS-CoV-2 positivity rates between non-clinical staff (e.g., clerical, administrative, information technology, secretarial, etc.) and frontline staff (e.g., nurses, doctors, allied healthcare professionals, porters, etc.) [39]. These results seem to suggest that several infections of HWs may be related to household or community contacts during the early phase of local 
spread and that the current isolation protocols and PPE appear sufficient to prevent high levels of nosocomial transmission to frontline staff [39].

\section{Risk assessment of HWs exposed to SARS-CoV-2}

The assessment of the risk is mandatory to identify the correct strategies to avoid SARS-CoV-2 infection in HWs. In the analysis of risk the type of contact, the risks related to environmental contamination and adherence to IPC measurements should be considered. Based on the level of exposure and the use of adequate PPE, a high-risk exposure was defined as a HW providing care to a COVID-19 case, or laboratory workers handling specimens from a COVID-19 case without the recommended PPE or with a possible breach of PPE. A low-risk exposure was defined as a HW wearing the recommended PPE. Although the correct use of PPE was not associated with SARS$\mathrm{CoV}-2$, in real-word, a deviation of protocol may be occurred with a possible infection. The exposure category, the risk assessment and the recommended monitoring are summarized in Table 2.

Risks associated with environmental contamination and the use of PPE are shown in Table 3. However, we underline that if all the required procedures, such as isolation possibly in negative pressure rooms, correct use of PPE, correct hygiene, are followed, the contamination of the hospital facilities would not be happened. However, knowing the extent of viral environmental contamination in COVID-19 wards is critical for improving safety practices and risk assessment for medical staff. Guo et al. [40] in a study conducted in Wuhan, China, analyzed air and surface samples of intensive care units (ICU) and general wards (GW). The authors found the rate of SARS-CoV-2 positivity much higher for the ICU than for the GW (43.5\% vs $7.9 \%)$; in particular, the rate of positivity was relatively high for floor swab samples ( $70 \%$ vs $15.4 \%$ ), suggesting that medical staff should perform stricter protective measures of infection control, such as disinfection of shoe soles before walking out of wards containing COVID-19 patients. The same authors assessed the risk for aerosol transmission of SARS-CoV2 collecting air in the isolation ward of the ICU (12 air supplies and 16 air discharges per hour) and GW (8 air supplies and 12 air discharges per hour) and obtained positive test results for $35 \%$ of ICU samples and $12.5 \%$ of GW samples.

In a study performed in healthcare facilities, the most contaminated objects were self-service printers (20.0\%), desktops/keyboards (16.8\%) and doorknobs (16.0\%); both hand sanitizer dispensers (20.3\%) and gloves (15.4\%) were the most contaminated PPE [23]. On the contrary, in the analysis of 90 samples of PPE from 30 HWs, Ong et al. [41] showed that none was SARS-CoV2 positive. However, it should be underscored that the time spent in the patient's room was very little, a median of $6 \mathrm{~min}$ (IQR: 5-10): $8 \mathrm{~min}$ for medical doctors, $7 \mathrm{~min}$ for nurses, and $3 \mathrm{~min}$ for cleaning staff.

Other factors to consider in risk assessment of HWs attending SARS-CoV-2 subjects include the duration of exposure, clinical symptoms of the patient (e.g., coughing likely increases exposure risk), whether the patient was wearing a facemask (which can efficiently block respiratory secretions from contaminating others and the environment), whether an aerosol generating procedure was performed and the type of PPE used by HWs. A study evaluating risk factors for COVID-19 in 72 exposed HWs in Wuhan, China who had acute symptoms identified as the risk factors working in a high risk versus general department (relative risk [RR]: 2.13, 95\% CI: 1.45-3.95), suboptimal hand washing before or after patient contact (RR: 3.10, 95\% CI: 1.43-6.73; and RR: 2.82, 95\% CI:1.11-7.18, respectively), longer working hours (log-rank $P=0.02$ ), and improper PPE use (RR: 2.82, 95\% CI: 1.11-7.18]) [42]. Min et al. [21] in a study on 30 SARS-CoV-2-positive HWs in China described all cases having a history of close direct contact (within 1 m) with COVID-19 patients, with an average number of 12 contacts (range: 7-16), and the average cumulative contact time of two hours (range: 1.5-2.7).

Table 2 Risk assessment and recommended monitoring of health workers (HWs) exposed to SARS-CoV-2

\begin{tabular}{|c|c|c|}
\hline Exposure category & Circumstances & Recommended monitoring \\
\hline High-risk exposure & $\begin{array}{l}\text { HW who has assisted a COVID-19 case and performed } \\
\text { procedures that generate aerosols or manipulated } \\
\text { biological samples during which direct exposure of } \\
\text { the skin or mucous membranes occurred without } \\
\text { adequate PPE. }\end{array}$ & $\begin{array}{l}\text { Stop all health care interaction with patients and } \\
\text { get tested for COVID-19; } \\
\text { Quarantine and daily self-monitoring of temperature } \\
\text { and respiratory symptoms for } 14 \text { days after the last day } \\
\text { of exposure to a COVID-19 patient. }\end{array}$ \\
\hline Medium-risk exposure & $\begin{array}{l}\text { HW who had prolonged close } \\
\text { contact with patients with COVID-19 not equipped with } \\
\text { the indicated PPE without direct exposure to the patient's } \\
\text { biological materials or in the event of non-compliance with } \\
\text { the procedures indicated. }\end{array}$ & $\begin{array}{l}\text { Daily self-monitoring of temperature and respiratory } \\
\text { symptoms for } 14 \text { days after the last day of exposure } \\
\text { to a COVID-19 patient and weekly active surveillance. }\end{array}$ \\
\hline Low-risk exposures & $\begin{array}{l}\text { HW who has assisted the case or manipulated biological } \\
\text { samples, with the indicated PPE, and without accidents or } \\
\text { episodes discordant with the indicated procedures. }\end{array}$ & $\begin{array}{l}\text { Daily self-monitor of temperature and respiratory } \\
\text { symptoms for } 14 \text { days after the last day of exposure } \\
\text { to a COVID-19 patient and weekly active surveillance. }\end{array}$ \\
\hline
\end{tabular}


Table 3 Evidences of environmental and PPE contamination and adherence to IPC procedures for SARS-CoV-2-infection

\begin{tabular}{|c|c|c|c|c|}
\hline \multirow[t]{2}{*}{ Author } & \multirow[t]{2}{*}{ Country } & \multicolumn{3}{|l|}{ Risk assessment } \\
\hline & & $\begin{array}{l}\text { Environmental contamination } \\
\text { of SARS-CoV-2 (\%) }\end{array}$ & $\begin{array}{l}\text { PPE contamination of } \\
\text { SARS-CoV-2 (\%) }\end{array}$ & $\begin{array}{l}\text { Adherence to IPC procedures or other risks } \\
\text { (associated to SARS-CoV-2 infection) }\end{array}$ \\
\hline Zhen-Dong et al., [31] & China & $\begin{array}{l}\text { - floor (70) } \\
\text { - computer mouse (75) } \\
\text { - trash can (60); } \\
\text { - sickbed handrail (42.9) }\end{array}$ & $\begin{array}{l}\text { - face shield or medical } \\
\text { mask (0) } \\
\text { - sleeve cuff (16.7) } \\
\text { - gloves }(25) \\
\text { - shoe sole }(50) \\
\text { - patients mask (40) }\end{array}$ & \\
\hline Ye et al., [33] & China & $\begin{array}{l}\text { - self-service printer } \\
\text { (patient only) (20) } \\
\text { - table top/keyboard (16.8) } \\
\text { - doorknob (16) } \\
\text { - telephone (12.5) } \\
\text { - medical equipment (not PPE) (12.5) } \\
\text { - wall/floor (5.6) }\end{array}$ & $\begin{array}{l}\text { - hand sanitizer } \\
\text { dispenser (20.3) } \\
\text { - gloves (15.4) } \\
\text { - eye protection or } \\
\text { facial shield (1.7) }\end{array}$ & \\
\hline Ong et al., [33] & Singapore & & $\begin{array}{l}\text { - One day HW's PPE } \\
\text { sampling (0) }\end{array}$ & \\
\hline Ran et al., [34] & China & & & $\begin{array}{l}\text { - Suboptimal hand washing before } \\
\text { (RR: 3.10,95\% Cl: } 1.43-6.73 \text { ) or after } \\
\text { (RR: 2.82, 95\% Cl: } 1.11-7.18 \text { ) patient contact } \\
\text { - Improper PPE use (RR: } 2.82,95 \% \text { Cl: } 1.11-7.18 \text { ) } \\
\text { - Work in a high risk versus general } \\
\text { department (RR: } 2.13,95 \% \text { Cl: } 1.45-3.95 \text { ) } \\
\text { - Longer work hours (log-rank } P=0.02 \text { ) }\end{array}$ \\
\hline Liu et al., [35] & China & & & $\begin{array}{l}\text { - Close direct contact (within } 1 \mathrm{~m} \text { ) with } \\
\text { COVID-19 patients } \\
\text { - Average number of } 12 \text { contacts (range: 7-16) } \\
\text { - Average cumulative contact time of two } \\
\text { hours (range: } 1.5-2.7 \text { ) }\end{array}$ \\
\hline Bartoszko et al., [37] & - & & & $\begin{array}{l}\text { - No differences in rate of infection between } \\
\text { medical mask and N95 respirators }\end{array}$ \\
\hline Ng et al., [38] & Singapore & & & $\begin{array}{l}\text { - No differences in rate of infection between } \\
\text { surgical mask and N95 respirators }\end{array}$ \\
\hline Jin et al., [39] & China & & & $\begin{array}{l}\text { - } 84.5 \% \text { of HWs thought they were infected in } \\
\text { working environment hospital } \\
\text { - } 41.8 \% \text { of HWs reported that their infection } \\
\text { was related to not maintaining protective } \\
\text { equipment and not utilizing common } \\
\text { equipment (masks and gloves) } \\
\text { - } 4.9 \% \text { of HWs thought they were infected in } \\
\text { daily life or community environment } \\
\text { - } 1 \% \text { of HWs thought that their infection was } \\
\text { due to the laboratory environments }\end{array}$ \\
\hline
\end{tabular}

Finally, to prevent SARS-CoV-2 infection in HWs, the use of appropriate PPE, including an N95 respirator and isolation gown, has been emphasized, but no difference in avoiding infection was observed between the use of medical mask and FFP2 or N95 mask. In fact, the results of a meta-analysis [43] highlighted that, compared with $\mathrm{N} 95$, the use of medical masks did not increase laboratory-confirmed viral respiratory infection, including coronaviruses (OR: 1.06; 95\% CI: $0.90-1.25 ; I^{2}=0 \%$;) or clinical respiratory illness (OR: 1.49; $95 \%$ CI: $0.98-$ $\left.2.28 ; I^{2}=78 \%\right)$. Only one trial evaluated coronaviruses separately and found no difference between the two groups $(P=0.49)[43]$. A study conducted in Singapore on 41 HWs exposed to aerosol-generating medical procedures for at least $10 \mathrm{~min}$ within $2 \mathrm{~m}$ of the undiagnosed COVID-19 patient found no case of SARS-CoV-2 infection in the $35 \mathrm{HWs}$ who wore surgical masks and in the six who wore N95 respirators [44].

Concluding on this point, for risk assessment, healthcare facilities should use questionnaires to proposed healthcare personnel [2] to investigate the type of healthcare personnel (e.g. medical doctor, registered nurse, etc.), type of healthcare facility (e.g. medical unit, ICU, etc.), type of contact (face to face/within $1 \mathrm{~m}$ or greater distance) and type of procedure performed on the confirmed COVID-19 patient (e.g. tracheal 
intubation, nebulizer treatment, tracheotomy, bronchoscopy, etc.). Furthermore, these questionnaires would be a useful tool to verify compliance with IPC such as the correct use of PPE in accordance with the type of procedure and the possible accident with body fluid/respiratory secretions during the care of COVID-19 patients. For example, in Wuhan University out of 103 COVID19 HWs who completed a validated questionnaire on the causes of infection, 43 (41.8\%) reported that their infection was related to not maintaining protective equipment and not utilizing common equipment (masks and gloves) when at close contact with infected cases. In particular, swabs of throat collection and physical examination were perceived as the procedures most likely causing their infection [45].

\section{Surveillance strategy of HWs exposed to SARS-CoV-2}

The surveillance of HWs exposed to SARS-CoV-2 is aimed at an early identification of the infected subjects to avoid the spread of a nosocomial outbreak. There are two main surveillance strategies for HWs, one passive or clinical and the other active or microbiological. The flow chart on healthcare surveillance strategies of HWs exposed to SARS-CoV-2 is shown in Fig. 2.

\section{Passive or clinical surveillance strategy}

A passive strategy foresees that all HWs self-assess for fever and/or a defined set of newly present symptoms suggestive of COVID-19. Exposed staff need to do active twice-daily fever surveillance for at least 14 days after the last exposure to the source case. If the HW complains of symptoms they should be sent home immediately after testing. However, the need to monitor also the mild symptoms of COVID-19 (myalgia, coughing and/or sore throat and/or common cold with or without fever) should be stressed. In fact, among the 14 SARSCoV-2-positive HWs due to exposure to two index patients in the neurosurgery ward in Wuhan, China, the main symptoms were myalgia or fatigue (100\%), fever (86\%) and a dry cough (71\%) [46].

The results from staff testing at Sheffield Teaching Hospitals in the UK between 16 and 29 March 2020 showed that of $1533 \mathrm{HWs}$ with symptoms suggestive of SARS-CoV-2, 282 (18\%) were positive [19]. In Germany, of $1353 \mathrm{HWs}$ with fever or respiratory symptoms, 86 (6\%) were SARS-CoV-2 positive; of these only $3 \%$ reported having been exposed to an inpatient known with COVID-19 prior to the onset of symptoms [47].

This strategy is simple and cost-effective. However, it has several disadvantages: the adherence is highly

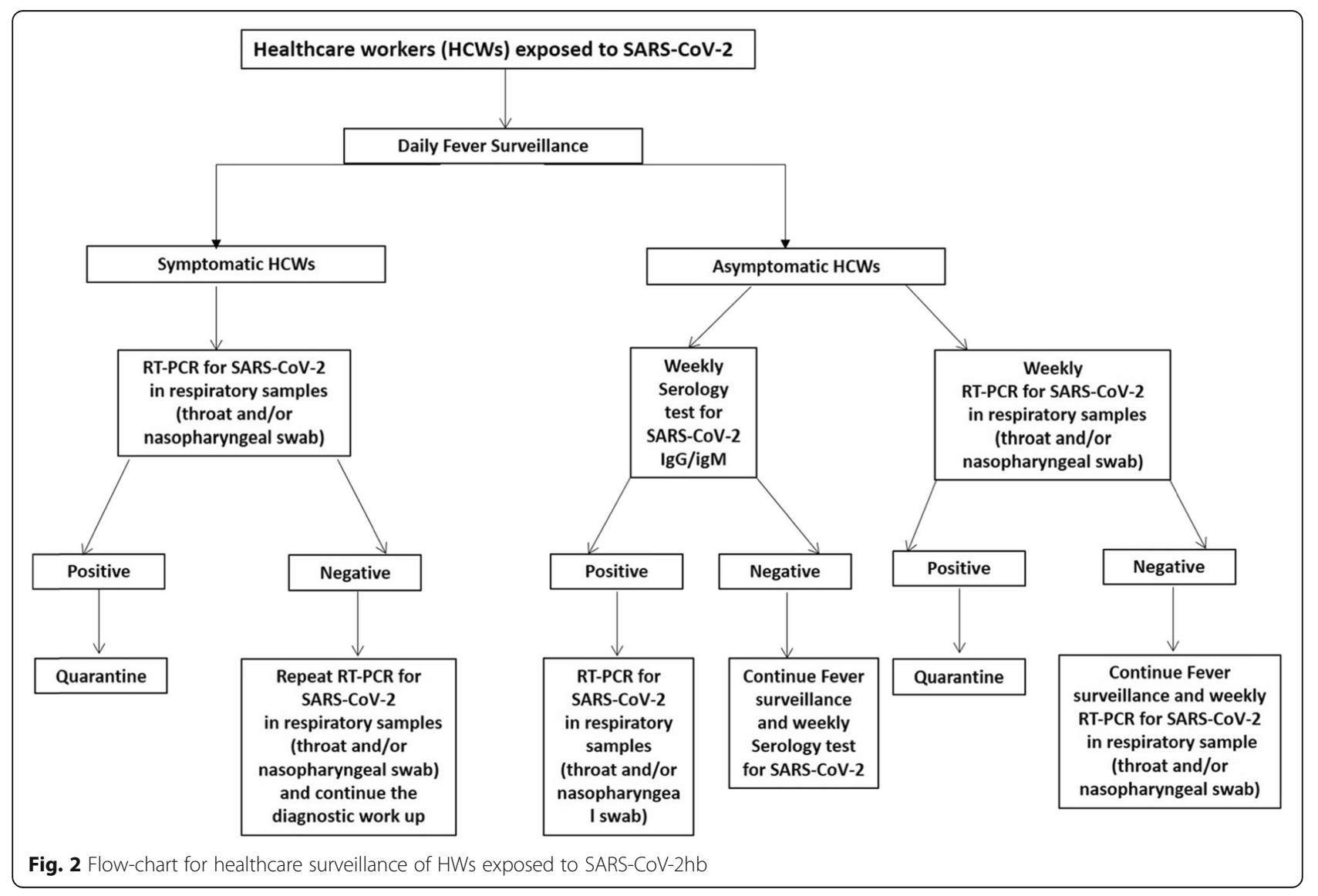


dependent on HW motivation and appropriate selfassessment of the risk; moreover, the asymptomatic and pre-symptomatic HWs are a potential source of infection not identified by the passive surveillance strategy [48]. Regarding this point, we underscore that SARS$\mathrm{CoV}-2$ infection may lead to a wide range of clinical presentations, from an asymptomatic or pauci-symptomatic form, which may be present in up to $85 \%$, to a severe acute respiratory syndrome [49]. In a study of COVID19 symptomatic and asymptomatic infection in a skilled nursing facility in Washington, USA, more than half (56\%) of the residents with positive test results were asymptomatic at the time of testing and most likely contributed to transmission [7]. Another study carried out in a large UK teaching hospital found that $3 \%$ of HWs tested positive for SARS-CoV-2 among 1032 asymptomatic HWs screened by real-time reverse transcription polymerase chain reaction (RT-PCR) [50].

\section{Active or microbiological surveillance strategy}

An active, or microbiological surveillance strategy foresees that all HWs be routinely tested for SARS-CoV-2 infection. The main diagnostic tools for surveillance in HWs exposed to COVID-19 are essentially real time RT-PCR in respiratory samples (throat and/or nasopharyngeal swab) and serology (point-of-care or laboratorybased) as surrogate for immunity for SARS-CoV-2.

RT-PCR is particularly useful to detect current infection with SARS-CoV-2. A recent meta-analysis performed by Kim et al. [51] considering 19 studies showed a pooled sensitivity of $89 \%$ (95\% CI: $81-94 \% ; I^{2}=90 \%$ ), while the positive predictive value (PPV) ranged from $47.3 \%$ to $98.3 \%$ and the negative predictive value (NPV) ranged from 93.4 to $99.9 \%$. Although RT-PCR represents a cornerstone for SARS-CoV-2 laboratory diagnosis, several limitations have been observed: inadequate sample collection or conservation or transportation, expensive test that requires qualified personnel and medium turnaround time.

Several serological immunoassays have been developed for the detection of SARS-CoV-2 viral proteins and antibodies in serum or plasma samples. The most widely used commercial tests are based on rapid lateral flow immunoassay (LFIA), automated chemiluminescence immunoassay (CLIA), enzyme-linked immune assay (ELISA) and rapid IgM/IgG tests, mainly based on immunoassay technology that provides results in 10-15 min [52]. The advantages of serological tests are that they are not very expensive, have easy collection sampling, use widely used techniques for all serological tests and do not need infrastructure, with rapid results for rapid serological tests. Thus, the rapid serological tests may be considered in active surveillance of HWs as an adding value tool. However, antibody responses to infection take days to weeks to be reliably detectable [53]. Therefore, negative results would not exclude SARS-CoV-2 infection, particularly among those with recent exposure to the virus [54]. The sensitivity of the rapid IgM-IgG combined antibody test varies in different studies [55, 56]. Li Z et al. [55] collected blood samples from 397 PCR confirmed COVID-19 patients and 128 negative patients at eight different clinical sites and found an overall testing sensitivity of $88.7 \%$ and specificity of $90.6 \%$. Instead, in a real-life study [56] performed in an emergency room department of a tertiary hospital in northern Italy on 110 subjects (30 healthy volunteers, 30 COVID-19-positive patients and 50 patients at their first access to an emergency room department with fever and respiratory syndrome), Cassaniti et al. found that the sensitivity of the rapid test was $18.4 \%$, specificity 91.7\%, while NPV was $26.2 \%$ and PPV was $87.5 \%$ in the patients enrolled [56].

In conclusion, owing to the great variability of the rates of sensitivity of the rapid serological tests they should be used with caution for screening HWs exposed to SARS-CoV-2, and RT-PCR, although expensive and difficult-to-repeat, remains the gold standard in active surveillance.

\section{Pre-exposure and post-exposure management of HWs exposed to SARS-CoV-2}

Currently, while active research on vaccine development is ongoing and although several drugs have been proposed as treatment regimens, there is no validated recommendation for pre- or post-exposure prevention of SARS-CoV-2 infection among HWs [57], and the data on this topic prevalently come from the outbreak of SARS in 2003 and MERS in 2012. A study conducted in Republic of Korea [58] highlighted the efficacy of postexposure prophylaxis (PEP) of ribavirin and lopinavir/ritonavir, given from 1 to 3 days after the last exposure until day 14, for $22 \mathrm{HWs}$ exposed to MERS-CoV patients: no instance of MERS-CoV infection was detected in these subjects. While, 6 out of $21 \mathrm{HWs}$ retrospectively enrolled in another 4 hospitals, exposed but without PEP, developed MERS-CoV infection.

As regards SARS-CoV-2, in vitro studies showed effectiveness of chloroquine (CQ) at entry and post entry level, suggesting its possible prophylactic activity also for this infection [59]. A systematic review in March 2020, considering three pre-clinical in vitro studies, showed that $\mathrm{CQ}$ and hydroxychloroquine (HCQ) have prophylactic effects against SARS-Cov2, but, actually, despite pre-clinical results being promising, in the absence of clinical studies to support the efficacy of CQ or HCQ in preventing COVID-19 CQ and HCQ are not indicate in this setting [60, 61]. In fact, several trials [62-64] are currently underway on the effectiveness of chloroquine 
as a pre-exposure prophylaxis (PrEP). For example, EPICOS [65] is a randomized clinical trial on HWs in Spain that aims to assess the efficacy of a daily single dose of tenofovir/emtricitabile (TDF/FTC), or $\mathrm{HCQ}$, or TDF/ FTC plus HCQ versus placebo as PrEP in $4000 \mathrm{HWs}$ (NCT04334928). A double-blinded, randomized placebo-controlled trial [66] is currently being conducted on 374 HWs in New York to determine whether PrEP, with a daily oral intake of $400 \mathrm{mg} \mathrm{HCQ}$, reduces the incidence of COVID-19 infection (NCT04352946).

Regarding the use of HCQ as PPE in a Korean study, it was administered to 189 patients and 22 HWs (who had initially tested negative for COVID) after exposure to a positive subject: none of the patients or HWs developed SARS-CoV-2-infection. However, in the absence of a control group these data cannot be considered conclusive on the effectiveness of HCQ as a PEP agent for COVID-19 [67]. However, we underline that recently the use of CQ and HCQ was banned by the WHO also in the therapeutic setting of patients with COVID-19.

\section{Conclusions}

This scoping review summarizes the evidence on the burden, risk assessment, surveillance and management of HWs exposed to SARS-CoV-2.

HWs are at a high risk of acquiring infection while caring for COVID-19 patients, due to long working hours, physical and psychological distress, inadequate training and shortage of personal protective equipment. Knowing the risk assessment of the various procedures and environmental contamination is of the utmost importance to implement the appropriate infection control measures. Surveillance is recommended for all HWs who are exposed to patients meeting the case definition for SARS-CoV-2, with the aim of identifying the occurrence of compatible symptoms and for infection control purposes to further limit in-hospital transmission clinical surveillance with fever/symptom assessment may lack information from asymptomatic/presymptomatic HWs. For this reason, it is reasonable that all exposed HWs are subjected, in addition to clinical monitoring, to microbiological surveillance using a swab or serological test, evaluating the pros and cons of the different methods according to the different settings. There are currently no robust data to give precise indications on PrEP and PPE.

However, this scoping review has some limitations: firstly, with new data being published on a daily basis, this review can only provide results up to 22 May 2020; moreover, publication bias may be not excluded. Although, due to the novelty of the epidemic, it cannot reflect the entire body of research on risk assessment and management of HWs exposed to COVID-19 worldwide, it will provide some evidences for future study.

\section{Acknowledgments}

We thank Vanvitelli COVID-19 group: Nicola Coppola, Caterina Sagnelli, Stefania De Pascalis, Maria Stanzione, Gianfranca Stornaiuolo, Angela Cascone, Salvatore Martini, Margherita Macera, Caterina Monari, Federica Calò, Andrea Bianco, Antonio Russo, Valeria Gentile, Clarissa Camaioni, Giulia De Angelis, Giulia Marino, Roberta Astorri, Ilario De Sio, Marco Niosi, Serena Borrelli, Vincenzo Carfora, Benito Celia, Maria Ceparano, Salvatore Cirillo, Maria De Luca, Marco Di Mauro, Grazia Mazzeo, Marco Migliaccio, Filiberto Fausto Mottola, Giorgio Paoli, Riccardo Ricciolino, Giorgio Spiniello, Nicoletta Verde.

\section{Authors' contributions}

FC and NC were involved in review concept and design and critical revision for important intellectual content. FC, AR, CC, SDP and Vanvitelli group performed the literature search and drafted the manuscript. FC, AR and NC were involved in the critical revision of the manuscript. The author(s) read and approved the final manuscript.

\section{Authors' information}

Nicola Coppola, Federica Calò, Antonio Russo, Stefania de Pascalis, Clarissa Camaioni: Department of Mental Health and Public Medicine, Section of Infectious Diseases, University of Campania Luigi Vanvitelli, Italy. Vanvitelli COVID-19 group: University of Campania, Luigi Vanvitelli, Naples, ITALY.

\section{Funding}

Not applicable.

\section{Availability of data materials}

All data generated or analyzed supporting the findings of this article are included within the article.

\section{Ethics approval and consent to participate}

Not applicable.

\section{Consent for publication}

Not applicable.

\section{Competing interests}

The authors have no relevant affiliations or financial involvement with any organization or entity with a financial interest in or financial conflict with the subject matter or materials discussed in the manuscript.

Received: 11 June 2020 Accepted: 16 September 2020

Published online: 07 October 2020

\section{References}

1. European Centre for Disease Prevention and Control. COVID-19 situation update worldwide, as of 3 June 2020. Stockholm: ECDC; 2020. Available from: https://www.ecdc.europa.eu/en/geographical-distribution-2019-ncovcases.

2. World Health Organization. Risk assessment and management of exposure of health care workers in the context of COVID-19: interim guidance. Geneva: World Health Organization; 2020. https://apps.who.int/iris/handle/1 0665/331496. License: CC BY-NC-SA 3.0 IGO

3. Sikkema RS, Pas SD, Nieuwenhuijse DF, O'Toole Á, Verweij J, van der Linden A, et al. COVID-19 in health-care workers in three hospitals in the south of the Netherlands: a cross-sectional study. Lancet Infect Dis. 2020;\$14733099(20):30527-2. https://doi.org/10.1016/S1473-3099(20)30527-2.

4. Barranco R, Ventura F. Covid-19 and infection in health-care workers: an emerging problem. Med Leg J. 2020;88(2):65-6. https://doi.org/10.1177/ 0025817220923694

5. Wang X, Zhou Q, He Y, Liu L, Ma X, Wei X, et al. Nosocomial outbreak of COVID-19 pneumonia in Wuhan, China. Eur Respir J. 2020;55(6):2000544. https://doi.org/10.1183/13993003.00544-2020.

6. Schwierzeck V, König JC, Kühn J, Mellmann A, Correa-Martínez CL, Omran H, et al. First reported nosocomial outbreak of severe acute respiratory syndrome coronavirus 2 (SARS-CoV-2) in a pediatric dialysis unit. Clin Infect Dis. 2020;ciaa491. https://doi.org/10.1093/cid/ciaa491.

7. Arons MM, Hatfield KM, Reddy SC, Kimball A, James A, Jacobs JR, et al. Public health-Seattle and King County and CDC COVID-19 investigation 
team. Presymptomatic SARS-CoV-2 infections and transmission in a skilled nursing facility. N Engl J Med. 2020;382(22):2081-90. https://doi.org/10.1056/ NEJMoa2008457.

8. World Health Organization. Infection prevention and control during health care when novel coronavirus ( $\mathrm{nCoV}$ ) infection is suspected. Interim guidance. [cited 2020 January 26] Available at: https://www.who.int/ publications-detail/infection-prevention-and-control-during-health-carewhen-novel-coronavirus-(ncov)-infection-is-suspected-20200125 Accessed 26 Jan 2020.

9. Liu Y, Ning Z, Chen Y, Guo M, Liu Y, Gali NK, et al. Aerodynamic analysis of SARS-CoV-2 in two Wuhan hospitals. Nature. 2020;582(7813):557-60. https:// doi.org/10.1038/s41586-020-2271-3.

10. Wong SCY, Kwong RT, Wu TC, Chan JWM, Chu MY, Lee SY, et al. Risk of nosocomial transmission of coronavirus disease 2019: an experience in a general ward setting in Hong Kong. J Hosp Infect. 2020;105(2):119-27. https://doi.org/10.1016/j.jhin.2020.03.036.

11. Centers for Disease Control and Prevention. Interim Infection Prevention and Control Recommendations for Patients with Suspected or Confirmed Coronavirus Disease 2019 (COVID-19) in Healthcare Settings. Update May 18, 2020. Available from: https://www.cdc.gov/coronavirus/2019-ncov/hcp/ infection-control-recommendations.html. Accessed 5 June 2020.

12. European Centre for Disease Prevention and Control. Infection prevention and control for COVID-19 in healthcare settings - third update. 13 May 2020. Stockholm: ECDC; 2020

13. European Centre for Disease Prevention and Control. Contact tracing: public health management of persons, including healthcare workers, having had contact with COVID-19 cases in the European Union - second update, 8 April 2020. Stockholm: ECDC; 2020.

14. Collection and Submission of Postmortem Specimens from Deceased Persons with Known or Suspected COVID-19, interim guidance, update June 4, 2020; https://www.cdc.gov/coronavirus/2019-ncov/hcp/guidancepostmortem-specimens.html. Accessed 5 June 2020.

15. Barton LM, Duval EJ, Stroberg E, Ghosh S, Mukhopadhyay S. COVID-19 autopsies, Oklahoma, USA. Am J Clin Pathol. 2020;153(6):725-33. https://doi. org/10.1093/ajcp/aqaa062.

16. Barranco $R$, Ventura F. The role of forensic pathologists in coronavirus disease 2019 infection: the importance of an interdisciplinary research. Med Sci Law. 2020;60(3):237-8. https://doi.org/10.1177/0025802420927825.

17. Keten D, Okdemir E, Keten A. Precautions in postmortem examinations in COVID-19 - related deaths: recommendations from Germany. J Forensic Legal Med. 2020;73:102000. https://doi.org/10.1016/j.jflm.2020.102000.

18. Hanley B, Lucas SB, Youd E, Swift B, Osborn M. Autopsy in suspected COVID-19 cases. J Clin Pathol. 2020;73(5):239-42. https://doi.org/10.1136/ jclinpath-2020-206522.

19. Keeley AJ, Evans C, Colton $H_{1}$ Ankcorn M, Cope A, State A, et al. Roll-out of SARS-CoV-2 testing for healthcare workers at a large NHS Foundation Trust in the United Kingdom, March 2020. Euro Surveill. 2020;25(14):2000433. https://doi.org/10.2807/1560-7917.ES.2020.25.14.2000433.

20. The Lancet. COVID-19: protecting health-care workers. Lancet. 2020 395(10228):922. https://doi.org/10.1016/S0140-6736(20)30644-9.

21. Liu M, He P, Liu HG, Wang XJ, Li FJ, Chen S, et al. Clinical characteristics of 30 medical workers infected with new coronavirus pneumonia. Zhonghua Jie He He Hu Xi Za Zhi. 2020;43(0):E016. https://doi.org/10.3760/cma.j.issn. 1001-0939.2020.0016 (in Chinese).

22. Istituto Superiore di Sanità (ISS). Integrated surveillance of COVID-19 in Italy. Rome, 2020 Available from: https://www.epicentro.iss.it/coronavirus/ bollettino/Infografica_22maggio\%20ITA.pdf.

23. Ye G, Lin H, Chen S, Wang S, Zeng Z, Wang W, et al. Environmental contamination of SARS-CoV-2 in healthcare premises. J Inf Secur. 2020:81(2): e1-5. https://doi.org/10.1016/j.jinf.2020.04.034.

24. Red Nacional de Vigilancia epidemiologica. Informe sobre la situación de COVID-19 en personal sanitario en España a 21 de mayo de 2020. Equipo COVID-19. RENAVE. CNE. CNM (ISCIII). Available from:https://www.isciii.es/ QueHacemos/Servicios/VigilanciaSaludPublicaRENAVE/ EnfermedadesTransmisibles/Documents/INFORMES/Informes\%20COVID-19/ COVID19\%20en\%20Espa\%C3\%B1a.\%20Situaci\%C3\%B3n\%20en\%2 OSanitarios\%20a\%2021\%20de\%20mayo\%20de\%202020.pdf.

25. Remuzzi A, Remuzzi G. COVID-19 and Italy: what next? Lancet. 2020 395(10231):1225-8. https://doi.org/10.1016/S0140-6736(20)30627-9.

26. World Health Organization. Report of the WHO-China Joint Mission on Coronavirus Disease 2019 (COVID-19). Geneva: WHO; 2020. Available from: https://www.who.int/docs/default-source/coronaviruse/who-china-jointmission-on-covid-19-final-report.pdf.

27. Coronavirus disease 2019 (COVID-19) in the EU/EEA and the UK - ninth update, 23 April 2020. Stockholm: ECDC; 2020.

28. Schwartz J, King CC, Yen MY. Protecting healthcare workers during the coronavirus disease 2019 (COVID-19) outbreak: lessons from Taiwan's severe acute respiratory syndrome response. Clin Infect Dis. 2020;71(15):858-60. https://doi.org/10.1093/cid/ciaa255.

29. Wang D, Hu B, Hu C, Zhu F, Liu X, Zhang J, et al. Clinical characteristics of 138 hospitalized patients with 2019 novel coronavirus-infected pneumonia in Wuhan, China. JAMA. 2020;323(11):1061-9. https://doi.org/10.1001/jama. 2020.1585.

30. CDC COVID-19 Response Team. Characteristics of health care personnel with COVID-19 — United States, February 12-April 9, 2020. MMWR Morb Mortal Wkly Rep. 2020;69(15):477-81. https://doi.org/10.15585/mmwr. mm6915e6.

31. European Centre for Disease Prevention and Control. Annual Epidemiological Report 2016 - Severe acute respiratory syndrome. Stockholm: ECDC; 2016. Available from: http://ecdc.europa.eu/en/ healthtopics/SARS/Pages/Annualepidemiologicalreport2016.aspx.

32. Oboho IK, Tomczyk SM, Al-Asmari AM, Banjar AA, Al-Mugti H, Aloraini MS, et al. 2014 MERS-CoV outbreak in Jeddah--a link to health care facilities. N Engl J Med. 2015;372(9):846-54. https://doi.org/10.1056/NEJMoa1408636.

33. Cowling BJ, Park M, Fang VJ, Wu P, Leung GM, Wu JT. Preliminary epidemiological assessment of MERS-CoV outbreak in South Korea, May to June 2015. Euro Surveill. 2015;20(25):7-13. https://doi.org/10.2807/15607917.es2015.20.25.21163.

34. Kim KH, Tandi TE, Choi JW, Moon JM, Kim MS. Middle East respiratory syndrome coronavirus (MERS-CoV) outbreak in South Korea, 2015: epidemiology, characteristics and public health implications. J Hosp Infect. 2017;95(2):207-13. https://doi.org/10.1016/j.jhin.2016.10.008.

35. World Health Organization. MERS-CoV situation update from the Eastern Mediterranean Region. 2019. Available from: http://www.emro.who.int/ pandemic-epidemic-diseases/mers-cov/mers-situation-update-november-2 019.html.

36. Kang SK. COVID-19 and MERS infections in healthcare workers in Korea. Saf Health Work. 2020;11(2):125-6. https://doi.org/10.1016/j.shaw.2020.04.007.

37. Reusken CB, Buiting A, Bleeker-Rovers C, Diederen B, Hooiveld M, Friesema I, et al. Rapid assessment of regional SARS-CoV-2 community transmission through a convenience sample of healthcare workers, the Netherlands, March 2020. Euro Surveill. 2020;25(12):2000334. https://doi.org/10.2807/ 1560-7917.ES.2020.25.12.2000334.

38. Folgueira MD, Muñoz-Ruipérez C, Alonso-López MA, Delgado R. SARS-CoV-2 infection in health care workers in a large public hospital in Madrid, Spain, during March 2020. MedRxiv. 2020. https://doi.org/10.1101/2020.04.07. 20055723.

39. Hunter E, Price DA, Murphy E, van der Loeff IS, Baker KF, Lendrem D, et al. First experience of COVID-19 screening of health-care workers in England. Lancet. 2020;395(10234):e77-8. https://doi.org/10.1016/S01406736(20)30970-3.

40. Guo ZD, Wang ZY, Zhang SF, Li X, Li L, Li C, et al. Aerosol and surface distribution of severe acute respiratory syndrome coronavirus 2 in hospital wards, Wuhan, China, 2020. Emerg Infect Dis. 2020;26(7):1583-91. https:// doi.org/10.3201/eid2607.200885.

41. Ong SWX, Tan YK, Sutjipto S, Chia PY, Young BE, Gum M, et al. Absence of contamination of personal protective equipment (PPE) by severe acute respiratory syndrome coronavirus 2 (SARS-CoV-2). Infect Control Hosp Epidemiol. 2020;41(5):614-6. https://doi.org/10.1017/ice.2020.91.

42. Ran L, Chen X, Wang Y, Wu W, Zhang L, Tan X. Risk factors of healthcare workers with corona virus disease 2019: A retrospective cohort study in a designated hospital of Wuhan in China. Clin Infect Dis. 2020;ciaa287. https:// doi.org/10.1093/cid/ciaa287.

43. Bartoszko JJ, Farooqi MAM, Alhazzani W, Loeb M. Medical masks vs N95 respirators for preventing COVID-19 in healthcare workers: a systematic review and meta-analysis of randomized trials. Influenza Other Respir Viruses. 2020;14(4):365-73. https://doi.org/10.1111/irv.12745.

44. Ng K, Poon BH, Kiat Puar TH, Shan Quah JL, Loh WJ, Wong YJ, et al. COVID19 and the risk to health care workers: a case report. Ann Intern Med. 2020; 172(11):766-7. https://doi.org/10.7326/L20-0175.

45. Jin $Y H$, Huang $Q$, Wang $Y Y$, Zeng $X T$, Luo LS, Pan ZY, et al. Perceived infection transmission routes, infection control practices, psychosocial 
changes, and management of COVID-19 infected healthcare workers in a tertiary acute care hospital in Wuhan: a cross-sectional survey. Mil Med Res. 2020;7(1):24. https://doi.org/10.1186/s40779-020-00254-8.

46. Wei XS, Wang XR, Zhang JC, Yang WB, Ma WL, Yang BH, et al. A cluster of health care workers with COVID-19 pneumonia caused by SARS-CoV-2. J Microbiol Immunol Infect. 2020;S1684-1182(20):30107-9. https://doi.org/10. 1016/j.jmii.2020.04.013

47. Kluytmans $M$, Buiting $A$, Pas $S$, Bentvelsen $R$, van den Bijllaardt $W$, van Oudheusden A, et al. SARS-CoV-2 infection in 86 healthcare workers in two Dutch hospitals in March 2020. medRxiv, 2020. https://doi.org/10.1101/2020. 03.23.20041913.

48. Black JRM, Bailey C, Przewrocka J, Dijkstra KK, Swanton C. COVID-19: the case for health-care worker screening to prevent hospital transmission. Lancet. 2020;395(10234):1418-20. https://doi.org/10.1016/S01406736(20)30917-X

49. Ruiyun BL, Pei S, Chen B. Substantial undocumented infection facilitates the rapid dissemination of novel coronavirus (SARS-CoV-2). Science. 2020; 368(6490):489-93. https://doi.org/10.1126/science.abb3221.

50. Rivett L, Sridhar S, Sparkes D, Routledge M, Jones NK, Forrest S, et al. Screening of healthcare workers for SARS-CoV-2 highlights the role of asymptomatic carriage in COVID-19 transmission. Elife. 2020;9:e58728. https://doi.org/10.7554/eLife.58728.

51. Kim $\mathrm{H}$, Hong $\mathrm{H}$, Yoon SH. Diagnostic performance of $\mathrm{CT}$ and reverse transcriptase-polymerase chain reaction for coronavirus disease 2019: a meta-analysis. Radiology. 2020;296(3):E145-55. https://doi.org/10.1148/radiol. 2020201343

52. Vashist SK. In vitro diagnostic assays for COVID-19: recent advances and emerging trends. Diagnostics (Basel). 2020;10(4):E202. https://doi.org/10 3390/diagnostics10040202.

53. Guo L, Ren L, Yang S, Xiao M, Chang D, Yang F, et al. Profiling early humoral response to diagnose novel coronavirus disease (COVID-19). Clin Infect Dis. 2020;71(15):778-85. https://doi.org/10.1093/cid/ciaa310

54. Cheng MP, Papenburg J, Desjardins M, Kanjilal S, Quach C, Libman M, et al. Diagnostic testing for severe acute respiratory syndrome-related coronavirus 2: a narrative review. Ann Intern Med. 2020;172(11):726-34. https://doi.org/ 10.7326/M20-1301.

55. Li Z, Yi Y, Luo X, Xiong N, Liu Y, Li S, et al. Development and clinical application of a rapid lgM-lgG combined antibody test for SARS-CoV-2 infection diagnosis. J Med Virol. 2020. https://doi.org/10.1002/jmv.25727.

56. Cassaniti I, Novazzi F, Giardina F, Salinaro F, Sachs M, Perlini S, et al. Performance of VivaDiag COVID-19 lgM/lgG Rapid Test is inadequate for diagnosis of COVID-19 in acute patients referring to emergency room department. J Med Virol. 2020. https://doi.org/10.1002/jmv.25800.

57. COVID-19 Treatment Guidelines Panel. Coronavirus Disease 2019 (COVID-19) Treatment Guidelines. National Institutes of Health. Available at https:// www.covid19treatmentguidelines.nih.gov/. Accessed [20 May 2020].

58. Park SY, Lee JS, Son JS, Ko JH, Peck KR, Jung Y, et al. Post-exposure prophylaxis for Middle East respiratory syndrome in healthcare workers. J Hosp Infect. 2019;101(1):42-6. https://doi.org/10.1016/j.jhin.2018.09.005.

59. Wang M, Cao R, Zhang L, Yang X, Liu J, Xu M, et al. Remdesivir and chloroquine effectively inhibit the recently emerged novel coronavirus (2019-nCoV) in vitro. Cell Res. 2020;30(3):269-71. https://doi.org/10.1038/ s41422-020-0282-0

60. Shah S, Das S, Jain A, Misra DP, Negi VS. A systematic review of the prophylactic role of chloroquine and hydroxychloroquine in coronavirus disease-19 (COVID-19). Int J Rheum Dis. 2020;23(5):613-9. https://doi.org/10. 1111/1756-185X.13842

61. Yao X, Ye F, Zhang M, Cui C, Huang B, Niu P, et al. In vitro antiviral activity and projection of optimized dosing design of hydroxychloroquine for the treatment of severe acute respiratory syndrome coronavirus 2 (SARS-CoV-2). Clin Infect Dis. 2020;71(15):732-9. https://doi.org/10.1093/cid/ciaa237.

62. Pre-exposure prophylaxis with hydroxychloroquine for high-risk healthcare workers during the COVID-19 pandemic (PrEP_COVID) . Available from: https://clinicaltrials.gov/ct2/show/NCT04331834. Accessed 5 June 2020

63. Does hydroxychloroquine before $\&$ during patient exposure protect healthcare workers from Coronavirus? (HEROs) Available from: https:// clinicaltrials.gov/ct2/show/NCT04374942. Accessed 5 June 2020.

64. COVID-19 PrEP HCW HCQ Study. Available from: https://clinicaltrials.gov/ct2/ show/NCT04354870. Accessed 5 June 2020.
65. Randomized clinical trial for the prevention of SARS-CoV-2 infection (COVID19) in healthcare personnel (EPICOS). Available from: https://clinicaltrials. gov/ct2/show/NCT04334928. Accessed 5 June 2020.

66. HEalth Care Worker pROphylaxis Against COVID-19: The HERO Trial (HERO) Available from: https://clinicaltrials.gov/ct2/show/NCT04352946. Accessed 5 June 2020.

67. Lee SH, Son H, Peck KR. Can post-exposure prophylaxis for COVID-19 be considered as an outbreak response strategy in long-term care hospitals? Int J Antimicrob Agents. 2020;105988. https://doi.org/10.1016/j.jantimicag. 2020.105988.

\section{Ready to submit your research? Choose BMC and benefit from:}

- fast, convenient online submission

- thorough peer review by experienced researchers in your field

- rapid publication on acceptance

- support for research data, including large and complex data types

- gold Open Access which fosters wider collaboration and increased citations

- maximum visibility for your research: over $100 \mathrm{M}$ website views per year

At BMC, research is always in progress.

Learn more biomedcentral.com/submissions 